\title{
Os Determinantes da Desaceleração Brasileira (2010-2015): uma Análise de Economia Política
}

The Determinants of the Brazilian Deceleration (2010-2015): A Political Economy Analysis

\section{Luciano Alencar Barros ${ }^{a}$}

\begin{abstract}
Resumo: O presente artigo busca fazer uma análise de economia política do processo de desaceleração do crescimento entre o fim do governo Lula e o primeiro mandato da presidente Dilma. Partindo da hipótese de que tal movimento se deu mais por fatores internos do que pela conjuntura externa, pretende-se discutir até que ponto a desaceleração da economia brasileira pós-2010 foi fruto de equívocos macroeconômicos por parte do governo, de uma ampla aliança capitalista visando desacelerar o crescimento ou ainda de uma combinação destes dois fatores.
\end{abstract}

Palavras-chave: Economia Política; Bloco no Poder; Economia Brasileira Contemporânea. JEL Classification: B51; E11; N16; P16.

\begin{abstract}
This paper aims to make a political economy analysis of the process of slowing growth between the end of Lula's administration and the beginning of Dilma's. Based on the hypothesis that such movement was primarily caused by endogenous factors rather than by external conditions, it intends to discuss to what extent the deceleration of the Brazilian economy post-2010 was a result of macroeconomic misconceptions on the part of the government, of a broad capitalist alliance aimed at slowing economic growth, or even of a combination of these two factors.
\end{abstract}

Keywords: Political Economy; Power Bloc; Contemporary Brazilian Economy. JEL Classification: B51; E11; N16; P16.

\footnotetext{
${ }^{\text {a }}$ Doutorando pelo Instituto de Economia da Universidade Federal do Rio de Janeiro.

E-mail: luciano.barros.ufrj@gmail.com. O autor contou com o apoio da Coordenação de Aperfeiçoamento de Pessoal de Nível Superior - Brasil (CAPES) - Código de Financiamento 001.
} 


\section{Introdução}

A economia brasileira passou por altos e baixos neste século. Partindo de uma taxa de crescimento baixa em 2001, acelerou seu crescimento a partir de então - apesar de alguns interregnos - até 2010, ano de maior crescimento. A partir de 2010, contudo, a economia começou a apresentar taxas de crescimento cada vez menores que, em meados de 2014, se tornariam negativas.

Este movimento de aceleração entre 2001 e 2007, forte redução da taxa de crescimento entre 2008 e 2009 por conta da crise financeira global, rápida recuperação em 2010 e desaceleração a partir de então foi um movimento mundial. A diferença é que o Brasil cresceu um pouco menos que o mundo entre 2001 e 2007, foi menos impactado e se recuperou mais rapidamente da crise, e sua desaceleração (pós 2010) foi muito mais acentuada do que a tendência mundial (Gráfico 1).

\section{Gráfico 1: Taxa de Crescimento Real do PIB (\%) - Mundo e Brasil}



Fonte: Organização para a Cooperação e Desenvolvimento Econômico

Ainda que seja um consenso que a aceleração da economia brasileira a partir de 2003 está relacionada com a dinâmica externa - aceleração do crescimento e do comércio global, aumento da liquidez e melhoria nos termos de troca brasileiros (PINTO, 2010; SERRANO E SUMMA, 2012) -, a questão de até que ponto a desaceleração pós-2010 derivou da reversão deste movimento internacional, e até que ponto foi resultado de escolhas de política econômica doméstica, é controversa. Se é verdade que o crescimento da economia brasileira foi liderado inicialmente (desde 2003) pelo setor externo, também o é que após 2006 a dinâmica interna ganha cada vez mais relevância, fato que, conjugado 
com uma série de medidas anticíclicas após a grande crise, ajuda explicar a rápida recuperação brasileira após 2008-2009. Mas e a desaceleração que se deu a partir de 2010?

O presente artigo se baseia na chamada abordagem do excedente, adotada pelo grupo de economia política da UFRJ, segundo a qual existem duas restrições ao crescimento econômico: a externa, relacionada à falta de divisas, e a política, relacionada à correlação de forças na sociedade e à orientação de política econômica que dela resulta (GAREGNANI, 1987; SERRANO E MEDEIROS, 2004). Em face ao cenário internacional favorável a partir dos anos 2000 (tirando o breve interregno da crise de 2008) de abundância de liquidez - expressa nas baixas taxas de juros norte-americanas - e de uma expansão comercial favorável à pauta exportadora brasileira, houve um grande aumento de reservas internacionais e uma melhora expressiva dos indicadores de vulnerabilidade externa do Brasil. Então, nesta visão, o fator determinante para a desaceleração analisada foi a restrição política (ainda que o cenário externo tenha contribuído para tal tendência).

Uma vez que a falta de divisas não constituiu uma restrição ao crescimento, entendese que tal restrição está relacionada a fatores domésticos relacionados à economia política. Neste sentido o presente artigo busca analisar este processo de desaceleração do crescimento entre o fim do governo Lula e o primeiro mandato da presidente Dilma. Pretende-se, assim, discutir até que ponto a desaceleração da economia brasileira pós-2010 foi fruto de equívocos macroeconômicos por parte do governo, de uma ampla aliança capitalista visando desacelerar o crescimento econômico, ou ainda de uma combinação destes dois fatores. Com este objetivo o presente trabalho se divide em mais três seções, além desta introdução. A seção dois realiza um sobrevoo sobre o período de 2003 a 2015 , mostrando como o desempenho macroeconômico se articula com o cenário externo e com as políticas econômicas adotadas; a seção três aborda o impacto desse resultado macroeconômico sobre a dinâmica política entre o bloco no poder e o Estado a partir de um referencial marxista, complementar à abordagem do excedente, baseado em Poulantzas (1977) e Pinto e Balanco (2014); e por fim a seção quatro conclui o artigo.

\section{Sobrevoo Macroeconômico}

Após o fraco desempenho dos governos de Fernando Henrique Cardoso (nos quais a variação real do PIB foi de, em média, 2,4\% ao ano) o presidente Lula foi eleito com o compromisso de realizar um governo mais comprometido com o crescimento econômico e o combate à desigualdade social. Porém, dado o cenário de vulnerabilidade macroeconômica (elevado endividamento externo) e a desconfiança dos mercados com a eleição do ex-sindicalista, o governo optou por realizar, em 2003, uma política extremamente contracionista, com ajuste fiscal e juros altos (apesar de estes caírem a partir de meados do ano). O resultado foi um crescimento real do produto, neste ano, de apenas 1,2\%. Depois disto, contudo, o cenário externo propiciou um gatilho para a aceleração do crescimento: o produto global passou a crescer a taxas cada vez maiores, com aumento do comércio internacional (o que acabou beneficiando o Brasil na medida em que, dada a inserção chinesa, aumentou o quantum exportado e melhorou os termos de troca 
brasileiros), baixos juros e abundância de liquidez internacional, aumento do fluxo de capitais e redução dos spreads para países emergentes (TEIXEIRA E PINTO, 2012; SERRANO E SUMMA, 2012).

A taxa de crescimento do produto brasileiro começa, a partir de 2003, a aumentar, inicialmente puxada pelas exportações e em seguida pelos componentes induzidos da demanda agregada. Sob a justificativa do rápido aquecimento da economia (que em 2004 cresceu 5,7\% em termos reais) e da elevação dos preços das commodities, o Banco Central (BC) começou a elevar os juros em meados de 2004 (Gráfico 2), o que, em conjunto com a diminuição da taxa de crescimento dos gastos, reduziu a taxa de crescimento do produto no ano seguinte (GIAMBIAGI et al., 2011). A partir daí, no entanto, a elevada entrada de dólares valorizou o câmbio e ajudou no controle da inflação ${ }^{1}$, além de ter viabilizado o acúmulo de reservas internacionais, reduzindo, assim, a vulnerabilidade externa (SERRANO, 2010; SERRANO E SUMMA, 2012). Este novo quadro possibilitou que o governo fizesse uma política econômica mais expansionista a partir de 2006.

\section{Gráfico 2: Taxa de Juros Selic (\% a.a.)}

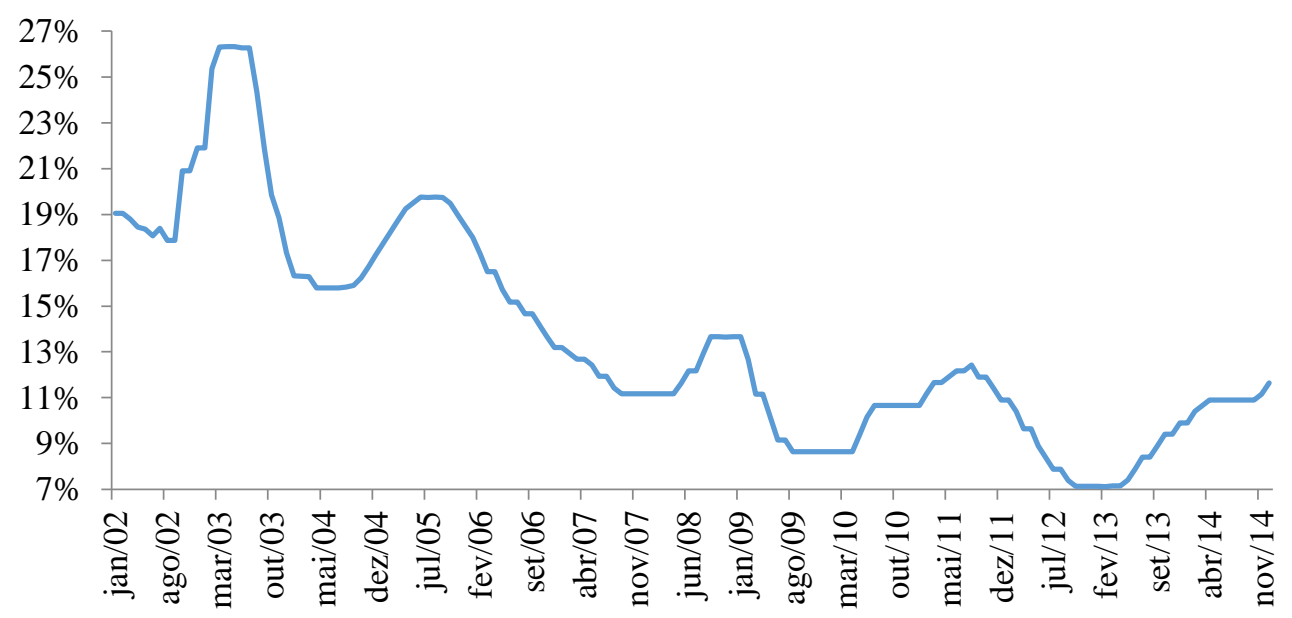

Fonte: Banco Central do Brasil

A partir de 2006 o governo reduziu os juros e aumentou seus gastos e transferências. Ao mesmo tempo ocorreu redução do desemprego, ganhos reais do salário mínimo e expansão do crédito, que, em conjunto, contribuíram para a forte aceleração da economia. Esta alcançou taxas de crescimento de 3,1\% em termos reais em 2005, 4\% em 2006 e 6\% no ano seguinte. A crise de 2007-2008, além de impactar diversas empresas brasileiras endividadas em dólar e reduzir os créditos comerciais internacionais, gerou expectativa de desvalorização cambial e levou o BC a elevar os juros no começo de 2008 (SERRANO E SUMMA, 2012).

\footnotetext{
${ }^{1}$ A valorização do câmbio barateia os produtos e insumos importados e torna menos atrativa a exportação (que em parte passa a ser destinada ao mercado interno), exercendo pressão baixista sobre os preços.
} 
A economia teve os três primeiros trimestres de 2009 de crescimento negativo, mas, em função da expansão do mercado interno nos anos anteriores e de uma série de medidas anticíclicas (como a redução dos juros e do superávit primário), se recuperou de forma rápida ao final de 2009, acelerando fortemente até meados de 2010 (Gráfico 3). Esta rápida saída da crise, em um cenário em que a economia global se recuperava lentamente, começou a atrair capitais, gerando vultosos superávits na conta capital e financeira (TEIXEIRA E PINTO, 2012; GONÇALVES, 2014).

\section{Gráfico 3: Variação Trimestral (\%) do PIB Real (frente ao mesmo período do ano anterior)}

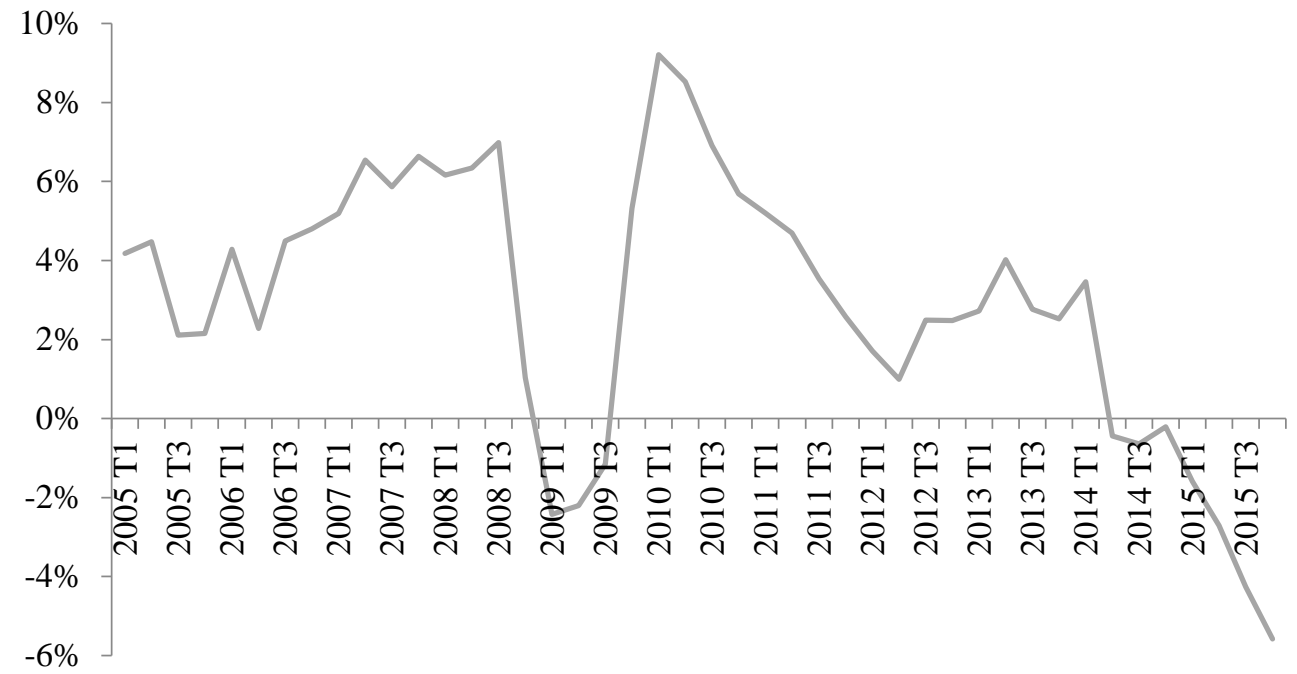

Fonte: Instituto Brasileiro de Geografia e Estatística (IBGE)/Sistema de Contas Nacionais

Esta forte aceleração do crescimento, somada ao fato de a inflação acumulada em doze meses ter superado o centro da meta de inflação de, então, 4,5\%, fez com que o BC optasse por uma elevação dos juros a partir do começo de 2010 (Gráfico 2). É preciso pontuar, contudo, que tal aumento da inflação explica-se principalmente pela aceleração dos preços dos bens transacionáveis internacionalmente: a inflação de tais bens (exportáveis e importáveis) se acelera continuamente a partir do final de 2009, chegando a alcançar, na segunda metade de 2011, o patamar de 20\% (acumulados em 12 meses), o que configura um forte choque de custo. A partir do final de 2010 o governo também passa a introduzir controle do fluxo de capitais (para evitar apreciação excessiva do câmbio frente ao aumento dos juros), medidas macroprudenciais para controlar o crédito ao consumidor ${ }^{2}$,

\footnotetext{
${ }^{2}$ São exemplos de medidas macroprudenciais o aumento do recolhimento compulsório; a elevação da taxação sobre operações financeiras relacionadas ao crédito ao consumidor; o aumento da parcela mínima paga na quitação dos saldos do cartão de crédito; e a elevação do montante mínimo de capital requerido para que os bancos realizem operações de créditos a prazos maiores.
} 
e inicia um processo de ajuste fiscal visando aumentar o superávit primário (SERRANO E SUMMA, 2012). Após o primeiro trimestre de 2010, quando o produto cresceu 9,1\% em termos reais em relação ao mesmo período do ano anterior, a economia começa a desacelerar, crescendo nos trimestres seguintes (em termos reais e também em comparação com os mesmos períodos do ano anterior) $8,5 \%$ ( $2^{\circ}$ tri), 6,9\% ( $3^{\circ}$ tri) e 5,6\% (4 $4^{\circ}$ tri), fechando o ano com um crescimento real anual de 7,6\% (gráfico 3). Desta forma a presidente Dilma, eleita neste mesmo ano, herdou uma economia com alta taxa de crescimento, mas em claro processo de desaceleração.

Este processo de desaceleração decorrente da adoção de uma política econômica contracionista (início do ajuste fiscal, restrições à expansão do crédito e elevação de juros) revela claramente um diagnóstico, equivocado, de inflação de demanda por parte do governo, mesmo frente ao forte choque de custos internacionais. Se o diagnóstico da inflação fosse de um choque de custos dos bens transacionáveis (cujos preços são cotados em dólar) não haveria necessidade de medidas macroprudenciais e nem de ajuste fiscal, e, além disso, o controle de capitais visando a não apreciação do câmbio seria (como foi) contraproducente ${ }^{3}$.

Para além desta desaceleração, o cenário externo começa a mudar de forma desfavorável para o Brasil de 2010 em diante: houve redução do crescimento mundial (Gráfico 1), desaceleração das exportações brasileiras (que cresceram 9,5\% em 2010 e apenas $2,9 \%$ no ano seguinte) e queda nos termos de troca depois da metade do ano (SERRANO E SUMMA, 2012). Porém, esta mudança apenas contribuiu para a tendência de desaceleração ditada pela política econômica doméstica. Neste sentido, cabe notar que as exportações têm um peso pequeno na demanda agregada brasileira (cerca de 11\%), sendo que muitas contém um elevado coeficiente de importação. Além disso, houve, no período analisado, superávit no balanço de pagamentos e um grande acúmulo de reservas internacionais ${ }^{4}$.

A política econômica, por sua vez, continuou a ser contracionista: elevação dos juros e restrição ao crédito, forte desaceleração do investimento público e opção pelo não aumento do salário mínimo. O resultado, previsível, foi a continuidade do processo de desaceleração do crescimento (Gráfico 3). No final de 2011 o governo decidiu reverter sua política monetária para estimular a economia, reduzindo os juros e estimulando o crédito, mas ao mesmo tempo manteve o ajuste fiscal. Tal ajuste se deu basicamente sobre o investimento público uma vez que, além de os gastos de custeio serem mais rígidos, o governo expandiu seus gastos em outras rubricas discricionárias, realizando parcerias público-privadas, isenções e desonerações. Optou-se também por deixar o câmbio se desvalorizar no intuito de estimular as exportações e o setor industrial voltado ao mercado doméstico (na medida em que o câmbio desvalorizado encarece os bens importados que competem com os produtos do setor).

\footnotetext{
${ }^{3}$ Para uma análise mais detalhada do processo ver Serrano e Summa (2012).

${ }^{4} \mathrm{O}$ debate sobre até que ponto o cenário externo impacta esse movimento de desaceleração pode ser visto em Serrano e Summa (2015) e Serrano e Melin (2015).
} 
Houve, em meados de 2012, um esboço de recuperação, mas a queda do superávit primário deu argumentos para quem defendia o discurso do descontrole do gasto público, ainda que as despesas crescessem a um ritmo menor do que nos anos anteriores.

\begin{abstract}
A redução do superávit primário a partir de 2011, resultado da combinação da queda da receita e aumento da despesa como proporção do PIB, levou à tese de "gastança". No entanto (...) esse forte aumento das despesas no PIB, no período recente, ocorreu justamente quando houve a menor taxa de crescimento das despesas. Esse fenômeno é facilmente explicado porque tratase de uma razão, cujo comportamento depende da evolução tanto do numerador quanto do denominador. Sendo assim, se a queda na taxa de crescimento do PIB for mais acentuada do que a queda na taxa de crescimento das despesas, a razão despesa/PIB irá se elevar. (DWECK E TEIXEIRA, 2017, p.12)
\end{abstract}

Isto levou a fortes cortes no investimento público em 2013. A partir deste ano o consumo privado começa a cair em função da redução da taxa de crescimento dos empregos formais e do salário real mínimo, bem como do esgotamento do ciclo de crédito. $\mathrm{O}$ resultado foi o colapso do investimento privado e com isso a abrupta redução da taxa de crescimento que chega a $0,1 \%$ em termos reais em 2014. É importante observar que a taxa de desemprego cai quase que continuamente de 2006 (com um breve interregno na crise) a 2014, mesmo com esta desaceleração (Gráfico 4). Neste sentido, existem quatro razões diretas para esta queda contínua no desemprego: 1) a queda na taxa de participação em decorrência das políticas sociais; 2) o fato de que, ainda que a economia tenha desacelerado, continuou a crescer; 3) alguns estímulos ao setor privado, concedidos a partir de 2012, tinham como contrapartida a manutenção dos empregos; e 4) o desemprego tende a responder com defasagem a mudanças na dinâmica econômica (dados todo o procedimento legal e o alto custo de contratar e demitir).

Novamente o fato de a redução da taxa de crescimento do PIB ser superior à redução da taxa de crescimento das despesas gerou deterioração fiscal (elevação da relação dívida pública/PIB) fortalecendo do discurso pró-austeridade, o que levou à aplicação de medidas mais contracionistas, e novamente à redução da taxa de crescimento, em um processo que se retroalimenta e configura uma espécie de "espiral contracionista".

A política monetária e fiscal contracionista, junto com a profunda desconfiança da burguesia, anulara as tentativas da nova matriz de elevar o investimento, o qual apresenta uma queda de 4,4\% em 2014. Com o declínio da atividade econômica, cai a arrecadação, deixando o Estado vulnerável às propostas de ajuste fiscal que se tornarão ubíquas. (SINGER, 2015, p. 53)

E como decorrência deste processo, onde uma política econômica contracionista desacelera o crescimento e deteriora as contas públicas, dando mais argumentos para quem defende políticas econômicas mais contracionistas (em um processo cumulativo), a economia foi desacelerando e passou a registrar taxas de crescimento negativas em 2015 e em 2016. 


\section{Estado, Bloco no Poder e Desaceleração Econômica}

Uma vez realizado um sobrevoo pela economia brasileira, faz-se necessário apresentar alguns conceitos de economia política que subsidiarão a análise do comportamento do governo no período. Neste sentido é importante adotar algum conceito de Estado e entender até que ponto este tem autonomia na definição da política econômica, e até que ponto está sujeito à pressão dos diferentes grupos de interesses organizados da sociedade brasileira.

O Estado pode ser definido, seguindo Poulantzas (1977) e Pinto e Balanco (2014), como o espaço político de interação entre os diferentes atores sociais. É possível dividir tais atores entre trabalhadores, indivíduos cujas necessidades materiais os obrigam a vender sua força de trabalho, e capitalistas, indivíduos que suprem tais necessidades a partir das rendas que obtém em função da propriedade dos meios de produção. Ambos constituem uma classe social em si (isto é, no sentido objetivo, dada sua inserção no processo produtivo) e podem ser divididos em subclasses. Para os fins do presente trabalho, contudo, basta a subdivisão da classe capitalista entre suas frações mais relevantes (em termos de participação no fluxo de rendas, no estoque de riqueza e na definição das políticas econômicas) no período 5 .

Outro conceito importante para a presente análise é o de autonomia relativa do Estado frente às classes sociais. A autonomia relativa seria a capacidade de o Estado direcionar a acumulação de capital e alterar a configuração das classes sociais e suas frações. O Estado pode oscilar entre um nível de autonomia relativa mais baixo ou mais alto. No extremo da autonomia (ótica estruturalista), o Estado se aproximaria da independência total frente às classes sociais, e, no extremo oposto, ausência de autonomia (ótica instrumentalista), ele seria um mero instrumento das classes e frações dominantes. Estas, para exercer poder dentro do Estado, comporiam o bloco no poder, uma espécie de aliança heterogênea (ou "unidade contraditória"), dentro da qual alguma(s) das frações dominantes exerce $(\mathrm{m})$ hegemonia (POULANTZAS, 1977; PINTO E BALANCO, 2014).

Como exposto na seção anterior, no primeiro ano do mandato de Lula o governo realizou um forte ajuste fiscal e adotou uma política de juros altos, o que, por um lado, atendia aos interesses da fração bancário-financeira (então fração hegemônica dentro do bloco do poder), e por outro implicou no baixo crescimento econômico observado naquele ano. A partir daí, contudo, a melhora no cenário externo começou a engendrar mudanças. Do ponto de vista das contas externas os superávits comerciais e na conta capital e financeira (principalmente após 2007) valorizaram o câmbio (arrefecendo a inflação) e permitiram um grande acúmulo de reservas (relaxando o problema crônico de restrição externa) $)^{6}$. No plano interno isto possibilitou o gatilho do crescimento, inicialmente puxado pelas exportações, favorecendo principalmente o agronegócio e os setores industriais produtores de commodities. Teixeira e Pinto (2012), contudo, observam que este

\footnotetext{
${ }^{5}$ Para uma análise detalhada das classes e suas frações no período ver Pinto (2010).

${ }^{6}$ A este respeito ver Medeiros e Serrano (2001).
} 
"favorecimento" foi muito mais fruto da dinâmica internacional do que de uma política pública deliberada:

O avanço dos segmentos industriais produtores de commodities e do agronegócio, durante o
governo Lula, teve muito mais a ver com a dinâmica internacional do que com políticas estatais.
Isso ficou evidente com a manutenção do regime de política macroeconômica, com juros
elevados, que gerou valorização cambial, impactando negativamente nos ganhos dos setores
mais do que compensados pelo aumento dos preços internacionais das commodities.
(TEIXEIRA E PINTO, 2012, p. 929)

A partir de 2006, com a inflação controlada e o bom resultado no balanço de pagamentos, o governo passou a fazer uma política mais expansionista, acelerando o crescimento de forma mais associada à dinâmica doméstica. Isto passa a favorecer os segmentos ligados a tal dinâmica, como a indústria e o comércio, além de permitir que a economia respondesse melhor à crise econômica de 2007-2008. As políticas anticíclicas em resposta a esta, contudo, aceleraram vigorosamente a economia brasileira que registrou seu maior crescimento em 2010. A partir daí, em função desta forte aceleração do crescimento e do aumento da inflação, o governo passou a realizar uma política mais contracionista, iniciando um projeto de ajuste fiscal, dificultando a expansão do crédito e elevando juros. Essas medidas revelam que, embora a fração bancário-financeira tenha perdido poder relativo para aquelas frações mais ligadas ao setor produtivo, ela não perdeu a hegemonia dentro do bloco no poder. Isto porque, por um lado, essas medidas restritivas deprimem a demanda do setor produtivo e encarecem seu financiamento, e por outro o ajuste fiscal sinaliza a intenção do governo de reduzir os demais gastos para priorizar o pagamento dos juros dos títulos da dívida pública, cujos detentores (em sua maior parte ligados à fração bancário-financeira), ainda são beneficiados pelo aumento dos juros.

Um ponto importante da aceleração da economia pós-2006 foi a esperada redução do desemprego, de 10\% em 2006 para um patamar de 5,5\% em 2012 e 2013 (Gráfico 4). Esta evolução da taxa de desempenho gerou um movimento duplo. Por um lado - quando se levam em conta também as políticas de expansão do crédito, elevação do salário mínimo real, transferência de renda, etc. - elevou o apoio da classe trabalhadora ao projeto do governo, e, em especial, à figura do presidente Lula. Isto fez com que a hegemonia da fração bancário-financeira, que antes era restrita ao bloco do poder (ou seja, era apoiada basicamente pelas outras frações da classe dominante), se ampliasse para o restante da sociedade (conjunto da classe trabalhadora). Por outro lado, esta redução do desemprego aumentou o poder de barganha da classe trabalhadora (vis-à-vis aos capitalistas), que, elevando sua confiança e consciência de classe, passou a fazer mais greves por melhores salários e condições de trabalho. Isto fica evidente quando se analisa o número de greves iniciadas por ano (Gráfico 4), uma vez que estas são um dos meios pelos quais a classe trabalhadora consegue obter parcelas maiores da renda nacional. Segundo dados do DIEESE, entre 2005 e 2009, quando a taxa de desemprego estava na casa dos $9 \%$, em média $80,8 \%$ dos trabalhadores obtiveram ganhos reais de salários, número que saltou para $90 \%$ entre 2010 e 2014, quando o desemprego caiu para o nível médio de 5,6\% (DIEESE, 2019). 


\section{Gráfico 4: Taxa de Desemprego e Número de Greves Iniciadas por Ano}

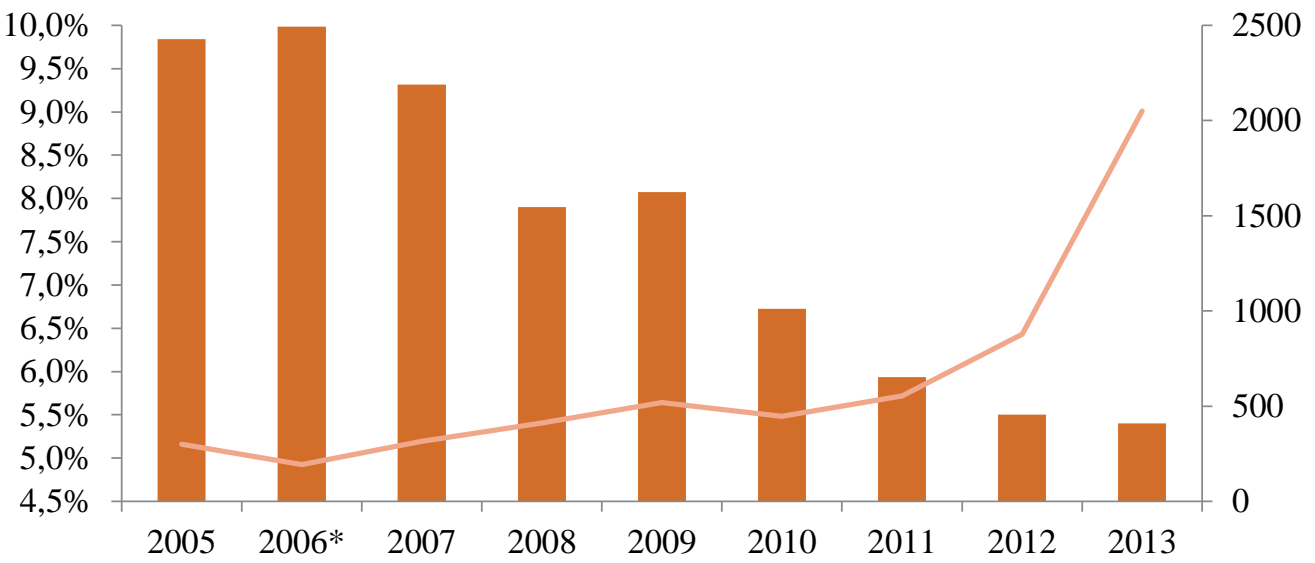

Taxa de desemprego (eixo esquerdo)

Número de greves iniciadas por ano (eixo direito)

Fonte: Pesquisa mensal do emprego/IBGE e Departamento Intersindical de Estatística e Estudos Socioeconômicos (DIEESE). *O número de greves de 2006 refere-se apenas ao primeiro semestre.

O primeiro movimento, de adesão (em especial dos extratos mais baixos) da classe trabalhadora ao projeto econômico vigente e, especificamente, à figura de Lula, configuraria o que Singer (2009) denominou de lulismo. Segundo o autor, a manutenção do modelo herdado de Fernando Henrique Cardoso, que representava os interesses da fração bancário-financeira e se materializava no tripé macroeconômico (superávit primário, câmbio flutuante e metas de inflação), teria agradado o caráter conservador da classe trabalhadora, enquanto as melhorias concretas nas condições de vida (em função das políticas de emprego, salário, crédito e transferência de renda) teriam atendido as suas aspirações materiais. Teixeira e Pinto (2012), no entanto, criticam a formulação do autor, afirmando que o lulismo representa mais do que uma "ponte com os de baixo" (que por sua vez não seriam necessariamente conservadores), mas também (e principalmente) um realinhamento com as frações dominantes, especialmente o setor financeiro, primário exportador e indústria de commodities, e da construção civil. Ainda que o lulismo não seja o foco do presente trabalho, sua dinâmica é importante para a compreensão do jogo de interesses que levou ao poder Dilma Rousseff, bem como as contradições enfrentadas no início deste governo.

É possível supor que, frente ao bom desempenho do governo Lula, sua liderança carismática, e ao enfraquecimento relativo da fração bancário-financeira dentro do bloco do poder (dado o aumento de poder das outras frações do bloco), o governo Dilma tenha começado com um elevado grau de autonomia relativa. Ainda assim, manteve a política 
contracionista iniciada no final do governo $\mathrm{Lula}^{7}$ até que a taxa de crescimento da economia (trimestral, frente ao mesmo período do ano anterior) atingisse, no início de 2012, o patamar de $1 \%$ (Gráfico 3).

Em 2012 há uma reviravolta: o governo opta por abandonar a política contracionista e tentar estimular o setor produtivo privado. Isto configuraria, nas palavras de Singer (2015), uma "guerra desenvolvimentista", na medida em que contrariaria a fração bancáriofinanceira para beneficiar os setores produtivos domésticos, como o exportador, o industrial e o comercial. O argumento de Singer é que a redução da taxa de juros básica e a "batalha do spread" (redução dos spreads puxada pelos bancos públicos) favoreceria o setor produtivo em detrimento ao financeiro, sendo aquele ainda favorecido pelo teórico aquecimento do mercado doméstico (dada a expansão do crédito), por incentivos para ramos específicos, parcerias público-privadas, isenções e desonerações, e pela desvalorização do câmbio (que favoreceria o setor industrial e os exportadores em geral) ${ }^{8}$. Ocorre que, na presença de taxas de crescimento cada vez mais baixas da demanda efetiva, a redução do investimento público esvaziou a parte desenvolvimentista e acentuou a parte da guerra. Isto porque tais medidas não foram suficientes para aquecer a demanda agregada, servindo mais para aumentar a lucratividade de alguns ramos do setor privado do que para estimular os investimentos.

(...) políticas de estimulo direto ao investimento que gerem aumento de margens de lucro, através de desonerações tributárias e redução do custo do investimento, como a redução da taxa de juros, ou desvalorizações cambiais que permitam a sustentação de margens de lucros mais altas aos produtores internos em setores expostos à concorrência externa em geral, por si só, não tem impacto positivo persistente sobre o investimento, pois, se não vem junto com alguma perspectiva de expansão da demanda, não tornam necessária a expansão da capacidade produtiva das empresas. (SUMMA E SERRANO, 2018, p.7)

Apesar de um esboço de reação da economia entre 2012 e 2013 (anos em que a economia cresceu respectivamente $1,8 \%$ e $2,7 \%$ em termos reais), isto não reverteu o processo de desaceleração, e ainda acirrou o conflito distributivo. Este processo de acirramento se deu tanto na base de apoio do governo (que disputava um orçamento que

\footnotetext{
${ }^{7}$ É razoável supor que o novo governo concordasse com o anterior no sentido de que a economia estava muito aquecida e que a inflação então observada era de demanda, bem como que seria interessante adotar uma estratégia (semelhante à do começo do primeiro mandato de Lula) de breve política ortodoxa seguida de expansionismo. Esta hipótese parece alinhada com a visão do então ministro da economia, Guido Mantega: "Fizemos o aperto em 2011 supondo que a economia mundial já estava em recuperação. Em 2011 puxamos o freio, dizendo: a gente faz um ajuste e depois retoma. Só que quando foi retomar, no segundo semestre de 2011, já tinha começado a crise europeia"." (Alves, Cristina; Fadul, Sergio; Alvarez, Regina; e Bonfanti, Cristiane. "Infraestrutura vai fazer Brasil crescer por uma década". O Globo, 15/9/2013, p. 31., Apud Singer, 2015, p. 51)

${ }^{8}$ Diversos autores concordam com esse "avanço desenvolvimentista" entre o final do segundo governo Lula e o primeiro de Dilma, como Bastos (2012, p.799): “(...) a conjuntura foi oportuna para que os grupos desenvolvimentistas do governo Lula avançassem sobre o domínio conservador das políticas macroeconômicas, processo que parece aprofundar-se no governo Dilma." Teixeira e Pinto (2012, p.933) também apontam esta tendência, resultante tanto da reconfiguração do bloco do poder (avanço de setores produtivos em detrimento ao setor financeiro) quanto dos "efeitos econômicos e ideológicos da crise financeira internacional".
} 
crescia a taxas decrescentes $^{9}$ ) quanto na sociedade como um todo. Se é bem verdade que havia conflito de interesses dentro do bloco do poder entre as frações da classe dominante, também é verdade que, frente a um Estado com elevada autonomia relativa e a uma classe trabalhadora fortalecida, tal bloco torna-se mais coeso para combatê-los por meio do desaquecimento da economia ${ }^{10}$. Este processo alinha-se muito bem com aquele descrito por Kalecki (1943) em "Aspectos políticos do pleno emprego”:

Nesta situação, uma poderosa aliança é provável de se formar entre as grandes corporações e os interesses rentistas, e que provavelmente há de se encontrar mais de um economista para declarar que a situação era manifestamente frágil. A pressão de todas essas forças, e em particular das grandes corporações - como regra, influentes em setores do governo - muito provavelmente induzirá o governo a voltar para a política ortodoxa (....). (KALECKI, 1943, p.6)

A partir de meados do primeiro mandato do governo Dilma, começa-se a se constituir essa poderosa aliança capitalista, liderada pela fração bancário-financeira, mas que com o tempo vai incorporando outras frações, como o agronegócio, o comércio, o setor de serviços e os industriais, compondo o que Singer (2015) denominou de "frente única burguesa". O objetivo era claro: reduzir o tamanho do Estado e baratear o custo da mão de obra por meio da desaceleração dos salários e da diminuição da proteção social da classe trabalhadora. Diante deste bloco no poder mais coeso, o Estado perde rapidamente sua autonomia, passando a ser refém dos seus interesses. Esta frente burguesa se utiliza do "elevado" patamar de inflação (que se manteve em uma média de 6,1\% ao ano entre 2010 e 2014), do quadro de desaquecimento econômico e da constante propaganda midiática a respeito da corrupção do setor público para criticar, repetitivamente, a intervenção do Estado na economia, apontando a deterioração fiscal como grande culpada pelos males da economia.

Finalmente o bloco no poder, agindo de forma coesa, vai exercendo diversas pressões e moldando a opinião pública a respeito da gravidade do quadro fiscal e da necessidade de austeridade. A adoção de uma política econômica recessiva desacelera a economia e deteriora as contas públicas, fortalecendo a tese da gastança. Trata-se de um processo cumulativo que vai se agravando, uma verdadeira "espiral contracionista" que desemboca na recessão iniciada em meados de 2014.

\footnotetext{
9 "De fato, um efeito colateral da multiplicação de demandas sobre uma arrecadação tributária líquida que aumenta a taxas decrescentes é a proliferação de conflitos do governo com sua ampla base de apoio." (Bastos, 2012, p.804)

10 “(...) os industriais "descobrem” que, dado o passo inicial de apoiar o ativismo estatal, estão às voltas com um poder que não controlam, o qual favorece os adversários de classe, até há pouco aliados. (...) a burguesia industrial volta-se "contra seus próprios interesses"(...) para evitar o que seria um mal maior: Estado demasiado forte e aliado aos trabalhadores." (Singer, 2015, p.66).
} 


\section{Conclusão}

Procurou-se demonstrar que, após uma aceleração do crescimento inicialmente puxada pelas exportações após 2003, a dinâmica doméstica, capitaneada por políticas econômicas expansionistas, ganhou cada vez mais importância no desempenho da economia. Em um cenário externo favorável houve uma quase que contínua (tirando o breve interregno da crise) aceleração do crescimento entre 2005 e 2010. Em que pese a reversão do cenário externo, principalmente de 2011 em diante, o presente trabalho se baseia na hipótese que a desaceleração pós-2010 se deu principalmente em função das políticas econômicas adotadas a partir do começo deste ano.

Depois da rápida aceleração do crescimento pós-crise (quando a economia chegou a crescer, em termos reais e em comparação com o mesmo período do ano anterior, 9,1\% no primeiro trimestre de 2010), o governo Lula, até então com elevada autonomia relativa (dados os anos anteriores de crescimento econômico e estabilidade inflacionária, sua popularidade e a reconfiguração do bloco no poder), decide frear a economia em 2010. Este movimento esteve relacionado com um diagnóstico equivocado de inflação de demanda no período (mesmo frente a um forte choque de oferta). O governo Dilma, concordando com este diagnóstico, manteve essa política no começo de 2011 , tendo em vista a realização de um breve ajuste para então realizar uma política econômica mais expansionista.

Frente ao forte desaquecimento da economia, o governo decide reverter sua política, no final de 2011, iniciando um pretenso expansionismo. Este consistiria em estimular o setor produtivo em detrimento ao setor financeiro, o que configuraria uma "guerra desenvolvimentista". Neste momento, o governo ainda contava com um bom grau de autonomia relativa, que a partir daí começa a declinar. $\mathrm{O}$ estímulo ao setor produtivo (privado) se deu em detrimento ao financeiro (e ao setor público também). Mas em um contexto de redução da taxa de crescimento da demanda efetiva, tal estímulo serviu muito mais para aumentar a lucratividade dos setores contemplados do que para induzir o investimento. $\mathrm{O}$ resultado foi a continuidade da desaceleração e o acirramento do conflito distributivo: muito mais guerra do que desenvolvimentismo.

Dadas a desaceleração da economia e a persistência da inflação, o governo foi perdendo apoio político. Em função de uma série de características do mercado de trabalho (como a defasagem da resposta do nível de emprego em relação a mudanças na dinâmica econômica), a classe trabalhadora continuou a elevar seu poder de barganha e a lograr obter ganhos reais de salários, enquanto o produto crescia a taxas cada vez menores. Isto levou a uma grande aliança dentro do bloco no poder para desaquecer a economia. E o governo, com sua política mal sucedida em estimular o crescimento, forneceu argumentos para tal aliança, na medida em que a economia se desaquecia e as contas públicas (relação dívida pública/PIB) se deterioravam. Neste momento, o governo perde autonomia relativa e fica mais sujeito à imposição de políticas contracionistas que reduzem a taxa de crescimento do produto e da arrecadação, ampliam a relação dívida/PIB, e assim fornecem ainda mais argumentos para o reforço do contracionismo, em um ciclo vicioso, uma "espiral contracionista", que joga a economia para baixo. 
A conclusão é que o governo gozava de um bom grau de autonomia no último ano do mandato de Lula e nos primeiros da Dilma, e optou por fazer uma política contracionista, o que desacelerou a economia. Quando tentou estimular o crescimento, o fez por mecanismos errados (desaceleração do investimento público, redução dos juros, desvalorização cambial e determinados estímulos fiscais ao setor privado) na medida em que deixou que a taxa de crescimento da demanda efetiva continuasse a cair. Com a continuidade do desaquecimento da economia e o acirramento do conflito distributivo (posto que a classe trabalhadora continuou elevando seu poder de barganha), formou-se uma aliança capitalista que reduziu fortemente a autonomia do governo e impôs-lhe uma política contracionista, jogando definitivamente a economia na recessão.

\section{Bibliografia}

BASTOS, P. A economia política do novo-desenvolvimentismo e do social desenvolvimentismo. Economia e Sociedade, Campinas: [s.n.], v. 21, Número Especial, pp. 779-810, 2012. DOI: https://doi.org/10.1590/S0104-06182012000400004

DIEESE. Balanço das Negociações dos Reajustes Salariais, 2005-2015. Disponível em: https://www.dieese.org.br/sitio/buscaDirigida?itemBusca=estudos\&comboBuscaDirigida $=$. Acesso em 20/02/2019.

DWECK, E.; TEIXEIRA, R. A política fiscal do governo Dilma e a crise econômica. IEUnicamp, Texto para Discussão 303, 2017.

GAREGNANI, P. Surplus approach to economics. In: EATWELL, J.; MILGATE, M.; Newman, P.; eds, The New Palgrave Dictionary of Economics. London: Macmillan, 1987.

GIAMBIAGI F. et al. Economia Brasileira Contemporânea: 1945-2010/ [organizadores Fabio Giambiagi... et al.]. - Rio de Janeiro: Elsevier, 2011.

GONÇALVES, R. Balanço crítico da economia brasileira nos governos do Partido dos trabalhadores. Revista da Sociedade Brasileira de Economia Política 37, 2014.

KALECKI, M. Political aspects of full employment. The Political Quarterly, v. 14, n. 4, p. 322-330, 1943. DOI: https://doi.org/10.1111/j.1467-923X.1943.tb01016.x

MEDEIROS, C. A.; SERRANO, F. Inserção externa, exportações e crescimento no Brasil. Polarização Mundial e Crescimento. Rio de Janeiro: Vozes, p. 39-75, 2001.

PINTO, E. Bloco no Poder e Governo Lula. Tese (Doutorado)-Instituto de Economia, Universidade Federal do Rio de Janeiro, 2010.

PINTO, E.; BALANCO, P. Estado, bloco no poder e acumulação capitalista: uma abordagem teórica. Revista de Economia Política, vol. 34, nº 1 (134), pp. 39-60, janeiromarço, 2014. DOI: https://doi.org/10.1590/S0101-31572014000100003 
POUlantZaS, N. Poder Político e Classes Sociais. São Paulo: Martins Fontes, 1977.

SERRANO, F. Juros, câmbio e o sistema de metas de inflação no Brasil. Brazilian Journal of Political Economy, v. 30, n. 1, p. 63-72, 2010.

DOI: https://doi.org/10.1590/S0101-31572010000100004

SERRANO, F.; MELIN, L. Aspectos Políticos do Desemprego: a guinada neoliberal do Brasil. 2015.

SERRANO, F.; SUMMA, R. Política macroeconômica, crescimento e distribuição de renda nos anos 2000. IV Encontro Internacional da Associação Keynesiana Brasileira, 2012.

SERRANO F.; SUMMA, R. Demanda agregada e a desaceleração do crescimento econômico brasileiro de 2011 a 2014. Center for Economic and Policy Research, ago, 2015. DOI: https://doi.org/10.1590/0103-6351/3549

SINGER, A. Raízes sociais e ideológicas do lulismo. Novos Estudos CEBRAP, n. 85, p. 83-102, 2009. DOI: https://doi.org/10.1590/S0101-33002009000300004

SINGER, A. Cutucando onças com varas curtas: o ensaio desenvolvimentista no primeiro mandato de Dilma Rousseff (2011-2014). Novos Estudos CEBRAP, n. 102, p. 39-67, 2015. DOI: https://doi.org/10.25091/s0101-3300201500020004

SERRANO, F.; MEDEIROS, C. O desenvolvimento econômico e a retomada da abordagem clássica do excedente. Revista de Economia Política, v. 24, n. 2, p. 94, 2004. DOI: https://doi.org/10.1590/0101-31572004-1625

SERRANO, F.; SUMMA, R. Conflito Distributivo e o Fim da "Breve Era de Ouro" da Economia Brasileira. Novos Estudos CEBRAP, v. 37, n. 2, p. 175-189, 2018.

DOI: http://dx.doi.org/10.25091/s01013300201800020002

TEIXEIRA, R.; PINTO, E. A economia política dos governos FHC, Lula e Dilma: dominância financeira, bloco no poder e desenvolvimento econômico. Economia e Sociedade, Campinas, v. 21, n. 4, p. 909-941, 2012.

DOI: https://doi.org/10.1590/S0104-06182012000400009 